\title{
Bertrand-Cournot Comparison in a Mixed Duopoly with Advertisement
}

\author{
Chul-Hi Park, Dmitriy Li, Sang-Ho Lee* \\ Department of Economics, Chonnam National University, Gwangju, South Korea \\ Email: "sangho@chonnam.ac.kr
}

Received 4 February 2016; accepted 3 April 2016; published 6 April 2016

Copyright (C) 2016 by authors and Scientific Research Publishing Inc.

This work is licensed under the Creative Commons Attribution International License (CC BY).

http://creativecommons.org/licenses/by/4.0/

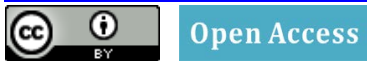

\begin{abstract}
We examine the Bertrand-Cournot comparison with advertisement in a differentiated mixed duopoly market, and compare with the social optimum. We show that not only both firms' quantities but also both firms' advertisements are higher (lower) in Cournot (Bertrand) than the social optimum. Thus, both firms engage in excessive (insufficient) advertisement in Cournot (Bertrand). We also show that despite lower both firms' prices in Cournot, both firms' profits and social welfare are strictly higher in Bertrand and thus, both firms prefer Bertrand to Counrnot.
\end{abstract}

\section{Keywords}

\section{Advertisement, Differentiated Mixed Duopoly, Bertrand-Cournot Comparison}

\section{Introduction}

Bertrand and Cournot models as leading modes of imperfect oligopoly competition are widely used in theoretical economics. Since Singh and Vives [1], it is well-known that Bertrand competition where firms compete in prices yields lower prices and profits and higher quantities and social welfare than Cournot competition where the firms compete in quantities. To date, however, the literature comparing Bertrand and Cournot outcomes has focused almost on the pure market competitions between profit-maximizing private firms.

Recently, there are some studies on the mixed market where profit-maximizing private firms coexist with welfare-maximizing public firm. ${ }^{1}$ For instance, Ghosh and Mitra [2] and Matsumura and Ogawa [3] found that the public firm's price is lower in Cournot than in Bertrand competition while the private firm's price can be higher or lower in Cournot ${ }^{2}$. Despite the ambiguity in price ordering between Bertrand and Cournot for the pri-

*Corresponding author.

${ }^{1}$ In reality, public firms in mixed markets are strongly concentrated in a few strategic sectors such as transportation, telecommunications, power generation, electricity, finance, manufacturing, and other energy industries.

${ }^{2}$ Recently, Nakamura [4] examined the comparisons between price and quantity competitions with network effect while Ohori [5] and Xu, et al. [6] examined them with emission tax. 
vate firm's price, comparison of quantities and profits gives unambiguous results. The public firm's quantity is higher in Cournot whereas the private firm's quantity is lower. Thus, contrary to standard findings, both firm's profits and social welfare are lower under Cournot, but consumer surplus is higher under Cournot.

We revisit the classic Bertrand-Cournot comparisons with advertising competition in a differentiated mixed duopoly market where a welfare-maximizing public firm competes with profit maximizing private firm. Comparing the results between Bertrand and Cournot equilibria, we show that most results in the previous literature on the mixed markets, e.g., Ghosh and Mitra [2] [7], Matsumura and Ogawa [3], Matsumura and Sunada [8], Haraguchi and Matsumura [9], Scrimitore [10], and Xu, et al. [6], still hold even though advertisement was taken into account. However, there are some more interesting findings when we compare the results with the social optimum. First, the public firm's quantity is strictly higher in Cournot while private firm's output is strictly lower in Bertrand. Also, both firms' quantities are higher (lower) in Cournot (Bertrand) than the social optimum, but Bertrand equilibrium is closer to the social optimum. Second, the public firm's advertisement is strictly higher in Cournot while private firm's advertisement is strictly lower in Bertrand. However, both firms' advertisements are higher (lower) in Cournot (Bertrand) than the social optimum and thus, both firms engage in excessive (insufficient) advertisement in Cournot (Bertrand). Third, both firm's prices are strictly higher in Bertrand while public firm's price in Cournotis equal to the social optimum. Finally, despite lower both firms' prices in Cournot, both firms' profits and social welfare are strictly higher in Bertrand and thus, both firms prefer Bertrand to Counrnot. This implies that irrespective of the degree of substitutability, Bertrand competition occurs in equilibrium and thus, Bertrand model should be used more in mixed oligopolies.

\section{The Basic Model}

Using a duopolistic competition model, each firm producing a differentiated good, we consider the case that the representative consumer has the following quadratic and strictly concave utility function:

$$
U\left(q_{1}, q_{2}\right)=a q_{1}+a q_{2}+z_{1} q_{1}+z_{2} q_{2}-\frac{1}{2}\left(q_{1}^{2}+2 b q_{1} q_{2}+q_{2}^{2}\right)
$$

where $q_{i}$ is the amount of consumption of good $i, p_{i}$ its price, $z_{i}$ is advertisement level of firm $i$, and $b \in(0,1)$ is the degree of substitutability between two products, $i=1,2$.

Then, utility maximization yields the linear inverse demand functions:

$$
\begin{aligned}
& p_{1}=a+z_{1}-q_{1}-b q_{2} \\
& p_{2}=a+z_{2}-b q_{1}-q_{2}
\end{aligned}
$$

Also, the direct demand functions are given by:

$$
\begin{aligned}
& q_{1}=\frac{a-a b+z_{1}-b z_{2}-p_{1}+b p_{2}}{1-b^{2}} \\
& q_{2}=\frac{a-a b+z_{2}-b z_{1}-p_{2}+b p_{1}}{1-b^{2}}
\end{aligned}
$$

We assume that firm 1, public firm, maximizes welfare, which is defined as the sum of consumer surplus and firms' profits:

$$
\operatorname{Max}_{q_{1}, z_{1}} W=a\left(q_{1}+q_{2}\right)+z_{1} q_{1}+z_{2} q_{2}-\frac{1}{2}\left(q_{1}^{2}+2 b q_{1} q_{2}+q_{2}^{2}\right)-c\left(q_{1}+q_{2}\right)-\frac{k}{2}\left(z_{1}^{2}+z_{2}^{2}\right)
$$

while firm 2, private firm, maximizes its own profit:

$$
\underset{q_{2}, z_{2}}{\operatorname{Max}} \pi_{2}=\left(p_{2}-c\right) q_{2}-k z_{2}^{2} / 2 .
$$

We assume that both firms have the same constant marginal production cost, $c>0$, and quadratic advertisement cost, $\frac{k z_{i}^{2}}{2}$, where $k>\frac{1}{1-b^{2}}$ to ensure the second-order conditions.

The timing of the game is as follows: In the first stage, both firm choose either the price or the quantity contract. In the second stage, according to the contract chosen in the first stage, both firms compete with Bertrand fashion where they choose price and advertising simultaneously, or compete with Cournot fashion where they choose quantity and advertising simultaneously. 


\section{The Analysis}

\subsection{Social Optimum}

As a benchmark, we analyze the social optimum, which maximizes social welfare:

$$
\underset{q_{1}, z_{1}, q_{2}, z_{2}}{\operatorname{Max}} W=a\left(q_{1}+q_{2}\right)+z_{1} q_{1}+z_{2} q_{2}-\frac{1}{2}\left(q_{1}^{2}+2 b q_{1} q_{2}+q_{2}^{2}\right)-c\left(q_{1}+q_{2}\right)-\frac{k}{2}\left(z_{1}^{2}+z_{2}^{2}\right)
$$

From the first-order conditions, the optimal levels of quantity, price and advertisement of each firm are as follows:

$$
q_{i}^{S O}=\frac{k(a-c)}{k+b k-1}, \quad z_{i}^{S O}=\frac{(a-c)}{k+b k-1}, \quad p_{i}^{S O}=c
$$

Note that marginal cost pricing is obtained at the social optimum. Then, the resulting profits of the firms and social welfare are as follows:

$$
\pi_{i}^{S O}=-\frac{\beta^{2} k(a-c)^{2}}{2\left(k^{2}-2 k-b^{2} k^{2}+1\right)^{2}}<0 \text { and } W^{S O}=\frac{k(a-c)^{2}}{k+b k-1}>0,
$$

where $\alpha=2 k-1-b k, \beta=k-1-b k, \gamma=1-b^{2}$. Note also that both firms earn negative profits with marginal cost pricing at the social optimum. However, the social welfare will be maximized at the social optimum.

\subsection{Bertrand Competition}

Consider the Bertrand competition case where both firm choose price and advertisement simultaneously. The first-order conditions for firms yields the following equilibrium quantity, price and advertisement level of each firm under Bertrand competition:

$$
\begin{gathered}
p_{1}^{B}=\frac{\beta \gamma a b k+c(\gamma k(\alpha+b)+1-2 k)}{\gamma\left(2 k^{2}-b^{2} k^{2}-k\right)+1-2 k}, \quad p_{2}^{B}=\frac{a k \beta \gamma+c\left(k^{2} \gamma\left(1+b-b^{2}\right)+1-2 k\right)}{\gamma\left(2 k^{2}-b^{2} k^{2}-k\right)+1-2 k} \text { and } \\
z_{1}^{B}=\frac{(a-c)\left(\alpha-b k\left(1+b-b^{2}\right)\right)}{\gamma\left(2 k^{2}-b^{2} k^{2}-k\right)+1-2 k}, \quad z_{2}^{B}=\frac{\beta(a-c)}{\gamma\left(2 k^{2}-b^{2} k^{2}-k\right)+1-2 k} .
\end{gathered}
$$

Note that both firms will set higher prices than marginal cost at the Bertrand equilibrium. Then, we have the following equilibrium outputs:

$$
q_{1}^{B}=\frac{k(a-c)\left(\alpha-b k\left(1+b-b^{2}\right)\right)}{\gamma\left(2 k^{2}-b^{2} k^{2}-k\right)+1-2 k} \text { and } q_{2}^{B}=\frac{\beta k(a-c)}{\gamma\left(2 k^{2}-b^{2} k^{2}-k\right)+1-2 k}
$$

The resulting profits of the firms and social welfare are as follows:

$$
\begin{gathered}
\pi_{1}^{B}=\frac{(a-c)^{2} k\left(k(1-b)\left(2-b^{2}\right)-1\right)\left((1+b)\left(b^{2} k+2 b k^{2}(1-b)^{2}\right)+1-2 k\right)}{2\left(\gamma\left(2 k^{2}-b^{2} k^{2}-k\right)+1-2 k\right)^{2}} \\
\pi_{2}^{B}=\frac{\beta^{2} k(a-c)^{2}(2 \gamma k-1)}{2\left(\gamma\left(2 k^{2}-b^{2} k^{2}-k\right)+1-2 k\right)^{2}} \\
W^{B}=\frac{(a-c)^{2} k\left[\alpha-2 \beta k-b^{2} k+\gamma k\left(\frac{\gamma^{2} k(\alpha+k-b k)}{2}+\gamma k(\beta-1)+\beta d-\alpha+b k\right)\right]}{\left(\gamma\left(2 k^{2}-b^{2} k^{2}-k\right)+1-2 k\right)^{2}}
\end{gathered}
$$


Note also that both firms earn positive profit at the Bertrand equilibrium. And the social welfare will be lower than the social optimum.

\subsection{Cournot Competition}

Consider the Cournot competition case where both firm choose quantity and advertisement simultaneously. The first-order conditions yield the following equilibrium quantity, price and advertisement level of each firm under Cournot competition:

$$
\begin{gathered}
q_{1}^{C}=\frac{\alpha k(a-c)}{2 k^{2}-3 k-b^{2} k^{2}+1}, q_{2}^{C}=\frac{\beta k(a-c)}{2 k^{2}-3 k-b^{2} k^{2}+1} \text { and } \\
z_{1}^{C}=\frac{\alpha(a-c)}{2 k^{2}-3 k-b^{2} k^{2}+1}, \quad z_{2}^{C}=\frac{\beta(a-c)}{2 k^{2}-3 k-b^{2} k^{2}+1} .
\end{gathered}
$$

Then, we have the following equilibrium prices.

$$
p_{1}^{C}=c \text { and } p_{2}^{C}=\frac{\beta a k-c\left(2 k-k^{2}-b k^{2}+b^{2} k^{2}-1\right)}{2 k^{2}-3 k-b^{2} k^{2}+1},
$$

where $\alpha=2 k-1-b k, \beta=k-1-b k, \gamma=1-b^{2}$. Note that public firm will set the marginal cost pricing while private firm will set higher price than marginal cost at the Cournot equilibrium.

The resulting profits of the firms and social welfare are as follows:

$$
\begin{aligned}
& \pi_{1}^{C}=-\frac{\alpha^{2} k(a-c)^{2}}{2\left(2 k^{2}-3 k-b^{2} k^{2}+1\right)^{2}}, \quad \pi_{2}^{C}=\frac{\beta^{2} k(2 k-1)(a-c)^{2}}{2\left(2 k^{2}-3 k-b^{2} k^{2}+1\right)^{2}} \\
& W^{C}=\frac{k(a-c)^{2}\left(\alpha\left(2+k^{2}-6 k\right)+2 \beta \gamma k^{2}+k^{2}(3 k-3 b k+2 b)\right)}{2\left(2 k^{2}-3 k-b^{2} k^{2}+1\right)^{2}}
\end{aligned}
$$

Note also that public firm earns negative profits while private firm earns positive profit at the Cournot equilibrium. And the social welfare will be lower than the social optimum.

\section{Comparisons}

We now compare the results under Bertrand and Cournot competitions with the social optimum. We will show that most results in the previous literature on the mixed markets still hold even though advertisement was taken into account. The following propositions provide some interesting findings when we compare the results with the social optimum.

Proposition 1. Public firm's output is strictly higher in Cournot whereas private firm's output is strictly higher in Bertrand. However, both firms' outputs are higher (lower) under Cournot (Bertrand) competition than the social optimum.

$$
\begin{aligned}
& \text { Proof. 1) } q_{1}^{B}-q_{1}^{C}=\frac{b k^{2}(a-c)\left(k^{2}(1-b)\left(b^{2}-2\right)+k\left(3-b-2 b^{2}+b^{3}\right)-1+b^{2}\right)}{\left(2 k^{2}-b^{2} k^{2}-3 k+1\right)\left(1-2 k+\gamma\left(2 k^{2}-b^{2} k^{2}-k\right)\right)}<0 \text { and } \\
& q_{1}^{B}-q^{S O}=\frac{\gamma b k^{2}(a-c)}{(k+b k-1)\left(1-2 d+\gamma\left(2 k^{2}-b^{2} k^{2}-k\right)\right)}>0 \Rightarrow q_{1}^{C}>q_{1}^{B}>q^{S O} \text {. } \\
& \text { 2) } q_{2}^{B}-q_{2}^{C}=\frac{\beta b^{2} k^{2}(a-c)\left(2 k-b^{2} k-1\right)}{\left(2 k^{2}-b^{2} k^{2}-3 k+1\right)\left(1-2 k+\gamma\left(2 k^{2}-b^{2} k^{2}-k\right)\right)}>0 \text { and } \\
& q_{2}^{B}-q^{S O}=\frac{\gamma(a-c) k^{2}\left(1-k+b^{2} k\right)}{(k+b k-1)\left(1-2 k+\gamma\left(2 k^{2}-b^{2} k^{2}-k\right)\right)}<0 \Rightarrow q^{S O}>q_{2}^{B}>q_{2}^{C}
\end{aligned}
$$


This proposition implies that the outputs of both firms are closer to the social optimum in Bertrand.

Proposition 2. Public firm's advertisement is strictly higher in Cournot whereas private firm's advertisement is strictly higher in Bertrand. However, both firms' advertisements are higher (lower) under Cournot (Bertrand) than the social optimum.

$$
\begin{aligned}
& \text { Proof. 1) } z_{1}^{B}-z_{1}^{C}=\frac{b k(a-c)\left(k^{2}(1-b)\left(b^{2}-2\right)+k\left(3-b-2 b^{2}+b^{3}\right)-1+b^{2}\right)}{\left(2 k^{2}-b^{2} k^{2}-3 k+1\right)\left(1-2 k+\gamma\left(2 k^{2}-b^{2} k^{2}-k\right)\right)}<0 \text { and } \\
& z_{1}^{B}-z^{S O}=\frac{\gamma b k(a-c)}{(k+b k-1)\left(1-2 d+\gamma\left(2 k^{2}-b^{2} k^{2}-k\right)\right)}>0 \Rightarrow z_{1}^{C}>z_{1}^{B}>z^{S O} . \\
& \text { 2) } z_{2}^{B}-z_{2}^{C}=\frac{\beta b^{2} k(a-c)\left(2 k-b^{2} k-1\right)}{\left(2 k^{2}-b^{2} k^{2}-3 k+1\right)\left(1-2 k+\gamma\left(2 k^{2}-b^{2} k^{2}-k\right)\right)}>0 \text { and } \\
& z_{2}^{B}-z^{S O}=\frac{\gamma(a-c) k^{2}\left(1-k+b^{2} k\right)}{(k+b k-1)\left(1-2 k+\gamma\left(2 k^{2}-b^{2} k^{2}-k\right)\right)}<0 \Rightarrow z^{S O}>z_{2}^{B}>z_{2}^{C} .
\end{aligned}
$$

This proposition implies that both firms engage in excessive advertising in Cournot whereas insufficient advertising in Bertrand.

Proposition 3. Both firms' prices are strictly higher in Bertrand. But, public firm's price is equal to (higher than) the social optimum under Cournot (Bertrand) while private firm's prices are strictly higher than the social optimum.

$$
\begin{gathered}
\text { Proof. 1) } p_{1}^{B}-p_{1}^{C}=\frac{\beta \gamma b k(a-c)}{\left(1-2 k+\gamma\left(2 k^{2}-b^{2} k^{2}-k\right)\right)}>0 \Rightarrow p_{1}^{B}>p_{1}^{C}=p^{S O}=c . \\
\text { 2) } p_{2}^{B}-p_{2}^{C}=\frac{\beta b^{2} k(a-c)(2 k-1)}{\left(2 k^{2}-3 k-b^{2} k^{2}+1\right)\left(1-2 k+\gamma\left(2 k^{2}-b^{2} k^{2}-k\right)\right)}>0 \text { and } \\
p_{2}^{C}-p^{S O}=\frac{\beta k(a-c)}{\left(2 k^{2}-3 k-b^{2} k^{2}+1\right)}>0 \\
\Rightarrow p_{2}^{B}>p_{2}^{C}>p^{S O}=c .
\end{gathered}
$$

Proposition 4. Both firms' profits are strictly higher in Bertrand. However, the profit of public firm in Cournot (Bertrand) is lower (higher) than the social optimum whereas the profits of private firm are strictly higher than the social optimum.

$$
\begin{gathered}
\text { Proof. 1) } \pi_{1}^{C}-\pi^{\text {SO }}=\frac{b k^{3}(a-c)^{2}\left(6 k-2-k^{2}\left(4+b-2 b^{2}\right)\right)}{2(k+b k-1)^{2}\left(2 k^{2}-b^{2} k^{2}-3 k+1\right)^{2}}<0, \pi_{1}^{B}>0, \pi^{S O}<0, \pi_{1}^{C}<0 \\
\Rightarrow \pi_{1}^{B}>\pi^{S O}>\pi_{1}^{C} \\
\text { 2) } \pi_{2}^{B}-\pi_{2}^{C}=\frac{k^{2}\left(\gamma b^{2}\left(k^{3}\left(8 \gamma+2 b^{4}\right)-k^{2}\left(b^{2}-4\right)^{2}+k\left(10-2 b^{2}\right)-2\right)-b^{6} k^{2}-2 b^{4} k+b^{4}\right)}{\left(\left(2 k^{2}-b^{2} k^{2}-3 k+1\right)\left(1-2 k+\gamma\left(2 k^{2}-b^{2} k^{2}-k\right)\right)\right)^{2}}>0 \Rightarrow \pi_{2}^{B}>\pi_{2}^{C}>\pi^{S O} .
\end{gathered}
$$

Proposition 5. Welfare is strictly higher under Bertrand.

$$
\text { Proof. } W^{B}-W^{C}=\frac{\beta^{2} b^{2} k^{3}(a-c)^{2}\left(\gamma k^{2}\left(b^{4}-6+k\left(4 \gamma+b^{4}\right)\right)-2 k^{2}-1-b^{2}+b^{4}+k\left(5+b^{2}-3 b^{4}\right)\right)}{2\left(1-3 k+b^{2} k+\left(2-3 b^{2}+b^{4}\right) k^{2}\right)^{2}}>0 .
$$

These proposition 4 and 5 imply that both public and private firms prefer Bertrand competition to Cournot 
competition. Thus, irrespective of the degree of substitutability, Bertrand competition will occur in an endogenous equilibrium. It implies that Bertrand model should be used more in differentiated mixed duopoly. Furthermore, this result is in stark contrast to the result in a private duopoly case where Cournot competition occurs in equilibrium. As discussed by Singh and Vives [1] and Matsumura and Ogawa [3], it indicates that privatization of a public firm changes the competition structure from Bertrand to Cournot. Therefore, if Cournot competition takes place after privatization, the welfare loss of privatization will be higher.

Remark 1: We can consider a sequential choice game in which advertisement is determined before firms decide quantities or prices. In such a game, the social optimum is the same, but the strategic effect between advertisement and quantity (or prices) can affect the equilibrium. However, we can find that the main results in the simultaneous choice game are robust.

Remark 2: We can consider a pure private market in which each firm chooses advertisements to maximize its own profit. We then compare the results of pure market with mixed market, and examine the welfare effect of privatization policy. We can show that as far as the cost efficiency gap between public firm and private firm is small, privatization will reduce the social welfare.

\section{Conclusion}

We have examined the Bertrand-Cournot comparison with advertising in a differentiated mixed duopoly and compare them with the social optimum. We have shown that not only both firms' quantities but also both firms' advertisements are higher (lower) in Cournot (Bertrand) than the social optimum. We have also shown that despite lower both firms' prices in Cournot, both firms' profits and social welfare are strictly higher in Bertrand. Thus, Bertrand competition will occur in an endogenous equilibrium, which indicates that Bertrand model should be used more in a differentiated mixed duopoly framework.

\section{References}

[1] Singh, N. and Vives, X. (1984) Price and Quantity Competition in a Differentiated Duopoly. Rand Journal of Economics, 15, 546-554. http://dx.doi.org/10.2307/2555525

[2] Ghosh, A. and Mitra, M. (2010) Comparing Bertrand and Cournot in Mixed Markets. Economics Letters, 109, $72-74$. http://dx.doi.org/10.1016/j.econlet.2010.08.021

[3] Matsumura, T. and Ogawa, A. (2012) Price versus Quantity in a Mixed Duopoly. Economics Letters, 116, $174-177$. http://dx.doi.org/10.1016/j.econlet.2012.02.012

[4] Nakamura, Y. (2013) Social Welfare under Quantity Competition and Price Competition in a Mixed Duopoly with Network Effects. Theoretical Economics Letters, 3, 211-215. http://dx.doi.org/10.4236/tel.2013.34035

[5] Ohori, S. (2014) Price and Quantity Competition in a Mixed Duopoly with Emission Tax. Theoretical Economics Letters, 4, 133-138. http://dx.doi.org/10.4236/tel.2014.42020

[6] Xu, L., Cho, S. and Lee, S. (2016) Emission Tax and Optimal Privatization in Cournot-Bertrand Comparison. Economics Modelling. Economic Modelling, 55, 73-82. http://dx.doi.org/10.1016/j.econmod.2016.02.008

[7] Ghosh, A. and Mitra, M. (2014) Reversal of Bertrand-Cournot Rankings in the Presence of Welfare Concerns. Journal of Institutional and Theoretical Economics, 170, 496-519. http://dx.doi.org/10.1628/093245614X13946181776030

[8] Matsumura, T. and Sunada, T. (2013) Advertising Competition in a Mixed Oligopoly. Economics Letters, 119, 183185. http://dx.doi.org/10.1016/j.econlet.2013.02.021

[9] Haraguchi, J. and Matsumura, T. (2014) Price versus Quantity in a Mixed Duopoly with Foreign Penetration. Research in Economics, 68, 338-353. http://dx.doi.org/10.1016/j.rie.2014.09.001

[10] Scrimitore, M. (2014) Quantity Competition vs. Price Competition under Optimal Subsidy in a Mixed Oligopoly. Economics Modelling, 42, 166-176. http://dx.doi.org/10.1016/j.econmod.2014.06.006 